\title{
Effects of ex vivo $\gamma$-Tocopherol on Airway Macrophage Function in Healthy and Mild Allergic Asthmatics
}

\author{
Marianne Geiser ${ }^{a, c}$ John C. Lay ${ }^{a, b}$ William D. Bennett ${ }^{a, c}$ Haibo Zhou ${ }^{a, d}$ \\ Xiaoyan Wang ${ }^{a, d}$ David B. Peden ${ }^{a-c}$ Neil E. Alexis ${ }^{a, b}$ \\ ${ }^{a}$ Center for Environmental Medicine, Asthma and Lung Biology, and Departments of b Pediatrics, ${ }^{\mathrm{c}}$ Medicine and \\ dBiostatistics, University of North Carolina School of Medicine, Chapel Hill, N.C., USA
}

\section{Key Words}

Allergy · Asthma · Flow cytometry · Host defense ·

Macrophages $\cdot$ Phagocytosis $\cdot \gamma$-Tocopherol

\begin{abstract}
Elevated inflammation and altered immune responses are features found in atopic asthmatic airways. Recent studies indicate $\gamma$-tocopherol (GT) supplementation can suppress airway inflammation in allergic asthma. We studied the effects of in vitro GT supplementation on receptor-mediated phagocytosis and expression of cell surface molecules associated with innate and adaptive immunity on sputum-derived macrophages. Cells from nonsmoking healthy $(n=6)$ and mild house dust mite-sensitive allergic asthmatics ( $n=$ 6) were treated ex vivo with GT (300 $\mu \mathrm{M})$ or saline (control). Phagocytosis of opsonized zymosan A bioparticles (Saccharomyces cerevisiae) and expression of surface molecules associated with innate and adaptive immunity were assessed using flow cytometry. GT caused significantly decreased $(p<0.05)$ internalization of attached zymosan bioparticles and decreased $(p<0.05)$ macrophage expression of CD206, CD36 and CD86 in allergic asthmatics but not in controls. Overall, GT caused downregulation of both innate and adaptive immune response elements, and atopic status appears to be an important factor.

Copyright $\odot 2013$ S. Karger AG, Basel
\end{abstract}

\section{Introduction}

Recent studies on the effects of the fat-soluble steroid hormone vitamins D and E suggest that dietary supplementation with these vitamins may be helpful for the prevention or in the treatment of inflammatory and immune-mediated diseases, including atopic asthma [17]. The antioxidant and nonantioxidant effects of the a-tocopherol isoform of vitamin E (AT) have been studied extensively [8]; however, $\gamma$-tocopherol (GT) has received much less scrutiny until recently. Studies on the differential regulatory effects of $\alpha$ and $\gamma$ isoforms are conflicting, whereas some studies indicate opposing regulatory function for these two isoforms, with AT having anti-inflammatory properties and GT exerting proinflammatory effects $[9,10]$, possibly due to differential effects on vascular endothelial cells [11]. In contrast, other investigators have clearly demonstrated potent anti-inflammatory effects of GT [7, 12-17].

Aside from its antioxidant and anti-inflammatory effects, the effects of vitamin $\mathrm{E}$ on innate immune function, particularly phagocytosis, have received little attention in either healthy or diseased individuals. Interestingly, altered monocyte and macrophage function in the airways is increasingly being appreciated as a key component in the pathophysiology of respiratory diseases [18-20]. For

\section{KARGER}

E-Mail karger@karger.com

www.karger.com/jin
(C) 2013 S. Karger AG, Basel

$1662-811 \mathrm{X} / 13 / 0056-0613 \$ 38.00 / 0$
Prof. Dr. Marianne Geiser

Institute of Anatomy, University of Bern

Baltzerstrasse 2

CH-3000 Bern 9 (Switzerland)

E-Mail geiser@ana.unibe.ch 
example, expression of cell surface receptors (CD64, CD14 and HLA-DR), phagocytosis and uptake of inhaled particles are modified in patients with asthma and cystic fibrosis compared to healthy controls. Numerous studies have shown diminished neutrophil phagocytic function in animals deficient in AT as well as the recovery or enhancement of innate immune function (phagocytosis and respiratory burst) of human and animal neutrophils following in vivo or in vitro supplementation with AT [21-25]. In contrast to studies on neutrophils, only a few conflicting studies have reported specifically on the effects of vitamin E on innate immune function in mononuclear phagocytes (monocytes and macrophages). Bergman et al. [22] found no effect of AT on phagocytosis by macrophages, while others [26,27] demonstrated enhanced phagocytosis and at least one study [28] showed a dose-dependent decrease in phagocytic activity. Since all these studies focused on the effects of AT, information on the effects of GT on innate immune function of macrophages is lacking.

We have previously shown that in vivo GT supplementation decreases systemic oxidative stress and cytokine responses of human monocytes in atopic asthmatic subjects [7], suggesting that GT may provide beneficial host defense responses in allergic asthma. It is unclear, however, whether GT supplementation has a beneficial effect on macrophage phagocytic function and whether there is differential benefit in allergic asthmatics versus healthy nonasthmatic volunteers. As an extension of the previous study, we used induced sputum-derived airway macrophages from healthy and mild allergic asthmatics to investigate potential differential effects of in vitro GT supplementation on specific macrophage functions including IgG-mediated phagocytosis and expression of surface molecules involved in phagocytosis and antigen presentation.

\section{Subjects and Methods}

\section{Subjects}

Subjects were recruited via an ongoing protocol for obtaining induced sputum samples specifically for in vitro studies, which was approved by the Committee on the Protection of the Rights of $\mathrm{Hu}$ man Subjects, School of Medicine, University of North Carolina at Chapel Hill Institutional Review Board. Written informed consent was obtained from all subjects before donation of sputum samples. A total of 14 volunteer subjects were recruited for this study. Two subjects were subsequently excluded for the following reasons: 1 healthy subject because of elevated eosinophil cell counts (6\%) and 1 asthmatic subject because of low sputum cell viability (42\%). The remaining 12 subjects comprised 6 healthy nonsmoking volunteers (skin test negative, 3 men and 3 women, $23.8 \pm 3.3$ years of age) and 6 nonsmoking volunteers with mild asthma and allergy to house dust mites (positive skin reaction test, 4 men and 2 women, $28.2 \pm 3.7$ years of age). All subjects underwent a thorough physical examination and had no history of recent respiratory tract infection. Asthmatic volunteers had a positive methacholine test and mild symptoms of asthma, as defined under the section 3 of the 2007 NHLBI guidelines for the diagnosis and management of asthma. Asthmatics used albuterol as needed, but none were taking steroids or anti-inflammatory medications to control symptoms. All subjects had a forced expiratory volume in $1 \mathrm{~s}\left(\mathrm{FEV}_{1}\right)$ of at least $80 \%$ of predicted for a normal population of similar height, weight, sex, race and age. All study participants were able to produce an adequate sputum sample ( $\geq 1 \times 10^{6}$ total cells, $\geq 50 \%$ cell viability, $\leq 20 \%$ squamous epithelial cells).

\section{Study Design}

The study was performed in vitro, using cells obtained from induced sputum. Sputum cells with a minimum viability of $50 \%$ were treated ex vivo with either GT or saline (control). Thereafter, GT-treated and untreated sputum macrophages were tested for their capacity to phagocytose opsonized zymosan A bioparticles (Saccharomyces cerevisiae) using flow cytometry (FCM) analysis. Concomitant analysis of surface molecules associated with innate and adaptive immunity was performed by FCM.

\section{Sputum Induction and Cell Processing}

Sputum was obtained by standard procedures [29, 30]. Briefly, subjects successively inhaled increasing concentrations of saline (3, 4 and 5\% saline) using a Devilbiss UltraNeb 99 ultrasonic nebulizer (Sunrise Medical, Somerset, Pa., USA) and donated sputum after each inhalation session of $7 \mathrm{~min}$. The three sputum samples were pooled. To obtain a cell-enriched 'select' sample, sputum cell aggregates (cellular mucus plugs) were manually selected from their surrounding fluid. Mucus was digested using $0.1 \%$ dithiothreitol (Sputolysin; Calbiochem, San Diego, Calif., USA) to free sputum cells, which were then washed and resuspended in Hanks' balanced salt solution and kept on ice until further treatment. Total cell counts and cell viability were determined using a Neubauer hemocytometer and trypan blue (Sigma, St. Louis, Mo., USA) exclusion staining. We expected a minimal yield of $1 \times 10^{6}$ cells (mainly macrophages and polymorphic neutrophils) and a cell viability of at least $50 \%$. Differential cell counts were determined on cytocentrifuged preparations stained the with Hema-Stain-3 kit (Fisher Diagnostics, Middletown, Va., USA).

\section{GT Treatment}

Cells were centrifuged and the pellet resuspended in RPMI 1640 cell culture medium (supplemented with $10 \%$ FCS) at a concentration of $1 \times 10^{6}$ cells $/ \mathrm{ml}$. Cells were then split into two samples, the GT-treated and the untreated control. Thereafter, cells were incubated with GT $(0.125 \mathrm{mg} / \mathrm{ml}=300 \mu \mathrm{M}$; Sigma $)$ or Dulbecco's phosphate-buffered saline (DPBS, control sample), respectively, for $1 \mathrm{~h}$ at $37^{\circ} \mathrm{C}$. This concentration was chosen because it had been used previously for in vitro studies in our laboratory [unpubl. observations]. The cells were centrifuged, resuspended in medium and their viability was assessed as described above. Cells were then diluted in medium to a concentration of $2 \times 10^{6}$ cells/ $\mathrm{ml}$. The GT-treated and the control cells were each split into three samples of equal cell numbers. 


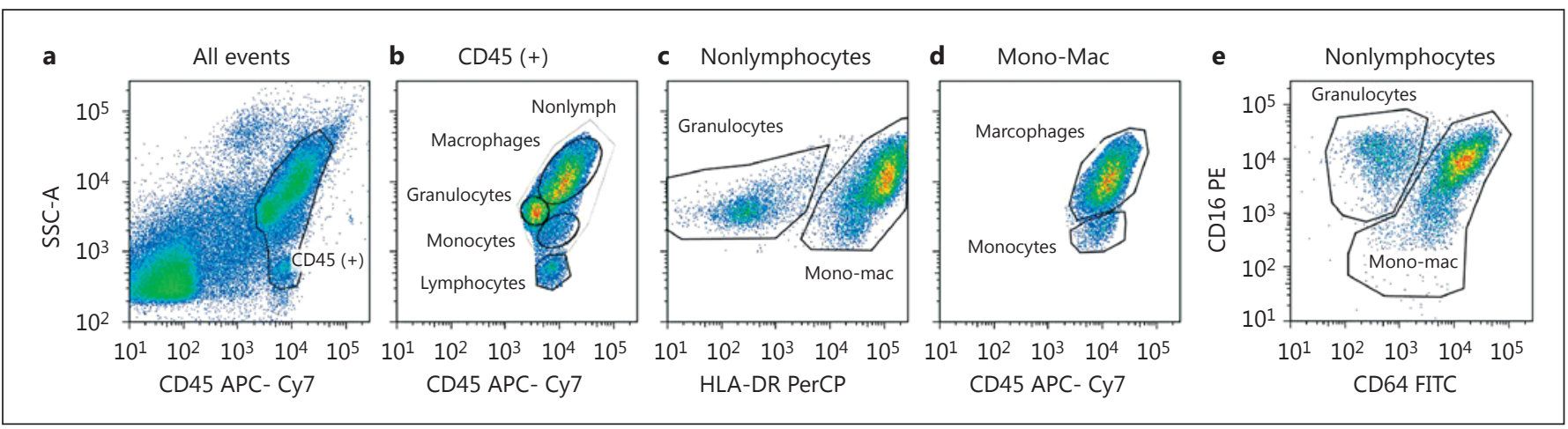

Fig. 1. Strategy for the identification and gating of sputum leukocytes. Subpopulations of CD45+ leukocytes (a) were identified using the differential expression of CD45, lineage markers and light scatter properties. b The general location of the various CD45+ subpopulations. Mononuclear phagocytes were differenti- ated from granulocytes based on differential expression of either HLA-DR (c), CD64 and CD16 (e) or CD14 (isotype control tube, not shown). $\mathbf{d}$ Macrophages and monocytes were gated based on CD45 expression and light scatter.
There was no evidence for any cytotoxicity of GT as used in our experiments: average cell viability $(\mathrm{n}=6)$ remained unaffected; it was $81.5 \pm 4.0 \%$ before and $81.3 \pm 4.0$ and $85.8 \pm 2.0 \%$ after GT or saline treatment, respectively. In addition, there was no evidence for cell necrosis (e.g. karyolysis, cell swelling or vacuoles) or apoptosis (shrinkage, pyknosis, karyorrhexis or blebbing) upon lightmicroscopic evaluation of cytospin preparations before and after GT or saline treatment. Furthermore, there was also no evidence for the induction of substantial cell death (necrosis/apoptosis) from surface marker analyses, as there was no general and systematic decrease in surface markers in all GT-treated samples.

Separate experiments determined that the solvent vehicle, dimethyl sulfoxide, which contained the dissolved GT, had no effects on cell viability, uptake of zymosan A bioparticles or expression of surface molecules at the final concentration used in this study.

\section{Particle Uptake}

We tested the effect of GT on in vitro particle uptake (phagocytosis) using fluorescein isothiocyanate (FITC)-labeled, IgG-opsonized S. cerevisiae zymosan A BioParticles (Molecular Probes, Eugene, Oreg., USA), as previously described [29, 31]. Briefly, 100 $\mu \mathrm{l}$ of sputum cells in culture media $\left(2 \times 10^{6}\right.$ cells $\left./ \mathrm{ml}\right)$ were incubated $\left(1 \mathrm{~h}\right.$ at $\left.37^{\circ} \mathrm{C}\right)$ with $100 \mu \mathrm{l}$ of opsonized FITC-labeled zymosan A bioparticles and $20 \mu$ of human serum (type AB; Cambrex Bioscience, Walkersville, Md., USA). After incubation, phagocytosis was stopped by diluting the reaction mixture with $200 \mu \mathrm{L}$ DPBS and immediately placing the samples on ice. The samples were analyzed immediately by FCM, as previously described [20, 32], using a FACSort flow cytometer (Becton-Dickinson, Franklin Lakes, N.J., USA). Briefly, the association of FITC-zymosan A with cells was assessed by measuring changes (histogram analysis) in mean fluorescence intensity (MFI) of zymosan-FITC-exposed sputum macrophages compared with unlabeled autofluorescent controls. Internalization of particles was assessed by adding $50 \mu \mathrm{l}$ of trypan blue to the cell suspension and measuring changes in comparison to zymosan-FITC-exposed sputum macrophages as above.

\section{Cell Surface Phenotypes}

We tested the effect of GT on the expression of surface molecules and phagocytic function using FCM as described in detail in previous publications $[29,30,33]$. In brief, $100 \mu$ lof cells $\left(1 \times 10^{6} /\right.$ $\mathrm{ml}, \mathrm{GT}$-treated and untreated control cells) were incubated with $10 \mu \mathrm{l}$ of fluorochrome-labeled monoclonal antibodies for $45 \mathrm{~min}$ at $4^{\circ} \mathrm{C}$, washed in DPBS and fixed in $500 \mu$ l of $0.5 \%$ paraformaldehyde. Samples were analyzed immediately using a BD LSR-II flow cytometer and FACSDiva 6.0 Software (BD Biosciences, San Jose, Calif., USA). Sputum leukocytes were differentiated from contaminating epithelial cells and debris based on a combination of lightscatter properties and differential expression of the pan-leukocyte marker CD45. Leukocyte subpopulations were further discriminated using specific gating strategies based on light scatter and differential expression of CD 45 and lineage-specific surface markers (fig. 1), including CD14, CD64, HLA-DR (monocytes and macrophages) and CD16 (neutrophils), as previously described [33]. Background and nonspecific fluorescence was determined using control cells incubated with appropriately labeled isotypic control antibodies. Reported MFIs for specific markers are corrected for background and nonspecific fluorescence.

We examined the expression of cell surface molecules associated with phagocytosis and innate immune function, including $\mathrm{Fc}$ receptors (CD64/Fc $\gamma$ RI, CD32/Fc $\gamma$ RII and CD16/Fc $\gamma$ RIII), the complement receptor (CD11b/CR3), the macrophage mannose receptor (CD206), the lipopolysaccharide receptor (mCD14) and tumor necrosis factor receptor-5 (CD40), which also functions as the B-cell costimulatory molecule. In addition, cell surface expression of CD36, a receptor for oxidized low-density lipoproteins (LDL), which has been shown to be downregulated by AT [34], was examined. We also assessed the expression of surface proteins associated with adaptive immune responses (antigen presentation and T-cell activation) including HLA-DR/MHC class II, CD86/ B7.2 costimulatory molecule and the B-cell costimulatory molecule CD40. Sources for monoclonal antibodies are listed in table 1. Appropriate isotype control antibodies were also obtained from these sources. 
Table 1. Specification of monoclonal antibodies used for FCM analysis of surface markers

\begin{tabular}{|c|c|c|c|c|c|}
\hline $\mathrm{CD} 11 \mathrm{~b} / \mathrm{CR} 3$ & ICRF44 & PE-CY5 & $\mathrm{BD}$ & Gran, Mac, Mono & Receptor for C3bi, phagocytosis, cell adhesion \\
\hline $\mathrm{CD} 16 / \mathrm{Fc} \gamma \mathrm{RIII}$ & $3 \mathrm{G} 8$ & $\mathrm{PE}$ & Coulter & PMN, Mac, NK & Phagocytosis, endocytosis \\
\hline $\mathrm{CD} 32 / \mathrm{Fc} \gamma \mathrm{RII}$ & 3D3 & FITC & $\mathrm{BD}$ & PMN, Mono, Mac & Phagocytosis, endocytosis \\
\hline $\mathrm{CD} 64 / \mathrm{Fc} \gamma \mathrm{RI}$ & 22 & FITC & Coulter & Mac, Mono & $\begin{array}{l}\text { Phagocytosis, antigen capture, } \\
\text { antibody-dependent cellular cytotoxicity }\end{array}$ \\
\hline $\mathrm{CD} 36$ & FA6.152 & FITC & Coulter & Mono, Mac & $\begin{array}{l}\text { Type-B1 scavenger receptor (SR-B), } \\
\text { oxidized LDL/HDL receptor }\end{array}$ \\
\hline $\mathrm{CD} 40$ & MAB89 & $\mathrm{PE}$ & Coulter & B cells, Mono, Mac, DC & $\begin{array}{l}\text { B cell costimulatory molecule, antigen presenta- } \\
\text { tion, B cell maturation and survival, TNFR-5 }\end{array}$ \\
\hline$\overline{\mathrm{CD}} 45$ & $2 \mathrm{D} 1$ & APC-Cy7 & $\mathrm{BD}$ & Pan leukocyte marker & $\begin{array}{l}\text { Leukocyte common antigen, } \mathrm{B} \text { and } \mathrm{T} \text { cell } \\
\text { activation and survival }\end{array}$ \\
\hline HLA-DR & L243(G46-6) & PerCP & $\mathrm{BD}$ & Mono, Mac, DC, B cells & MHC II, antigen presentation \\
\hline
\end{tabular}

Coulter = Beckman Coulter, Brea, Calif., USA; BD = BD Biosciences; Mac = macrophages; Mono = monocytes; Gran = granulocytes; $\mathrm{PMN}=$ polymorphonuclear leukocytes (neutrophils); DC = dendritic cells; NK = natural killer cells; LDL = low-density lipoprotein; $\mathrm{HDL}=$ high-density lipoprotein.

Table 2. Sputum and cell recovery, viability, total and differential cell counts and cells per milligram of nonsquamous cells in select sputum determined using a Neubauer hemocytometer and stained cytocentrifuged sputum cell preparations

\begin{tabular}{|c|c|c|c|c|c|c|c|c|c|}
\hline $\begin{array}{l}\text { Subjects } \\
(\mathrm{n}=12)\end{array}$ & $\begin{array}{l}\text { Selected } \\
\text { sputum weight } \\
\text { mg }\end{array}$ & $\begin{array}{l}\text { Ratio select/ } \\
\text { total sputum } \\
\text { weight }\end{array}$ & $\begin{array}{l}\text { Total cells } \\
\times 10^{6}\end{array}$ & $\begin{array}{l}\text { Cells/mg } \\
\mathrm{n}\end{array}$ & $\begin{array}{l}\text { Viable } \\
\%\end{array}$ & $\begin{array}{l}\text { PMN } \\
\%\end{array}$ & $\begin{array}{l}\text { Macro- } \\
\text { phages } \\
\%\end{array}$ & $\begin{array}{l}\text { Eosino- } \\
\text { phils } \\
\%\end{array}$ & $\begin{array}{l}\text { Lympho- } \\
\text { cytes } \\
\%\end{array}$ \\
\hline Normal $(n=6)$ & $2,599(501)$ & $0.34(0.06)$ & $9.78(2.68)$ & $4,682(1,243)$ & $83.60(3.50)$ & $54.48(12.24)$ & $42.97(12.06)$ & $0.34(0.21)$ & $2.22(1.02)$ \\
\hline Range & $1,116-4,470$ & $0.13-0.56$ & $2.68-20.95$ & $1,770-7,900$ & $70.21-94.27$ & $21.21-93.47$ & $4.52-76.22$ & $0.00-1.01$ & $0.00-7.07$ \\
\hline Allergic $(n=6)$ & $3,010(606)$ & $0.34(0.07)$ & $5.95(1.33)$ & $2,136(370)$ & $85.00(2.51)$ & $48.86(8.06)$ & $45.87(7.89)$ & $2.30(1.59)$ & $2.98(0.56)$ \\
\hline Range & $1,621-5,468$ & $0.10-0.56$ & $3.52-11.90$ & $1,372-3,471$ & $77.83-92.24$ & $28.50-77.66$ & $32.14-67.01$ & $0.00-10.20$ & $1.02-4.57$ \\
\hline All $(\mathrm{n}=12)$ & $2,804(380)$ & $0.34(0.04)$ & $7.86(1.54)$ & $3,409(728)$ & $84.30(2.07)$ & $51.67(7.04)$ & $44.42(6.89)$ & $1.32(0.82)$ & $2.60(0.57)$ \\
\hline Range & $1,116-5,468$ & $0.10-0.56$ & $2.68-20.95$ & $1,372-7,900$ & $70.21-94.27$ & $21.21-93.47$ & $4.52-76.22$ & $0.00-10.20$ & $0.00-7.07$ \\
\hline
\end{tabular}

Data are presented as the mean (SEM) unless otherwise specified. No significant differences were detected between the two groups (normal vs. allergic) for any of the variables. PMN = Polymorphonuclear leukocytes (neutrophils). Macrophages include monocytes and all macrophage populations. There were no basophils recorded in any of the subjects.

\section{Statistical Analysis}

In this study, sputum cells from the same subject were treated with either GT or saline. Thus GT or no treatment became a within-subject (repeated-measure) factor, while the allergy status was a between-subject factor. To explore the potential interaction effect between GT and allergy status, we conducted a formal statistical investigation of the potential interaction by using multivariate analysis techniques. In particular, a two-way repeated-measure model was fitted for each outcome variable. To look for the GT effect in the healthy or the allergic group, we fitted a one-way repeat- ed-measure ANOVA model on individual groups. A p value less than the overall 0.05 significance level was considered statistically significant. Throughout the paper, the p values reported were based on the aforementioned analyses unless otherwise stated. Descriptive statistics such as number of observations, mean, SEM and range (minimum, maximum) are used to summarize the continuous outcome variables. Group comparisons were carried out using the SAS/STAT user's guide (version 9.1; SAS Institute, Cary, N.C., USA). Spearman's correlation was performed using GraphPad Prism v5.04 software (GraphPad Software, San Diego, Calif., USA). 
Table 3. Statistics summary of $\mathrm{p}$ values for each outcome variable

\begin{tabular}{|c|c|c|c|c|c|c|c|}
\hline \multirow[t]{2}{*}{ Parameter } & \multirow[t]{2}{*}{ Population } & \multicolumn{3}{|c|}{ 2-way ANOVA (all subjects) } & \multicolumn{3}{|c|}{ 1-way ANOVA } \\
\hline & & allergic & GT & allergic $\times$ GT & $\begin{array}{l}\text { healthy } \\
\text { GT }\end{array}$ & $\begin{array}{l}\text { allergic } \\
\text { GT }\end{array}$ & $\begin{array}{l}\text { baseline healthy } \\
\text { vs. allergic }\end{array}$ \\
\hline \multirow[t]{4}{*}{ Zymosan } & Phagocytic, \% & 0.11 & 0.53 & $0.02 *$ & 0.16 & 0.057 & 0.07 \\
\hline & Int part/cell & 0.06 & 0.99 & 0.73 & 0.69 & 0.83 & 0.08 \\
\hline & Int, $\%$ & 0.52 & 0.10 & 0.22 & 0.79 & $0.03 *$ & 0.40 \\
\hline & Ratio Int/Ext & 0.56 & $0.04^{*}$ & 0.42 & 0.44 & $0.02 *$ & 0.51 \\
\hline CD206 & $\mathrm{Mac}$ & 0.08 & $0.02 *$ & 0.53 & 0.19 & $0.04^{*}$ & 0.14 \\
\hline CD64 & $\mathrm{Mac}$ & 0.37 & 0.87 & 0.95 & 0.95 & 0.85 & $0.05^{*}$ \\
\hline CD16 & $\mathrm{Mac}$ & 0.93 & $0.03 *$ & 0.62 & 0.18 & 0.13 & 0.84 \\
\hline CD32 & $\mathrm{Mac}$ & 0.17 & 0.34 & 0.16 & 0.21 & 0.66 & 0.21 \\
\hline CD14 & $\mathrm{Mac}$ & 0.30 & 0.21 & 0.42 & 0.57 & 0.29 & 0.27 \\
\hline CD11b & $\mathrm{Mac}$ & 0.56 & 0.73 & 0.73 & 1.00 & 0.13 & 0.52 \\
\hline CD36 & $\mathrm{Mac}$ & 0.82 & $0.03^{*}$ & 0.15 & 0.57 & $0.02 *$ & 0.96 \\
\hline CD86 & $\mathrm{Mac}$ & 0.81 & $0.004^{*}$ & 0.66 & 0.07 & $0.03^{*}$ & 0.76 \\
\hline HLA-DR & $\mathrm{Mac}$ & 0.12 & 0.08 & 0.11 & 0.81 & 0.11 & 0.07 \\
\hline CD40 & $\mathrm{Mac}$ & 0.79 & $0.03^{*}$ & 0.64 & 0.08 & 0.23 & 0.71 \\
\hline
\end{tabular}

Mac $=$ Macrophages $;$ Int $=$ internal; Ext $=$ external. ${ }^{*} \mathrm{p}<0.05$.

\section{Results}

\section{Cell Yield, Viability and Differential Counts of Sputum-Derived Cells}

Total and differential cell counts and other sputum parameters for normal subjects $(n=6)$ and those with allergic asthma $(n=6)$ are presented in table 2 . Average cell viability in all subjects was $84.30 \pm 2.07 \%$ (range 70.21 $94.27 \%$ ), hence well above the minimally required $50 \%$ viability. Compared to healthy controls, asthmatic subjects produced slightly higher total and select sputum weights, fewer total cells per milligram and had an expectedly greater percentage of eosinophils in the select sample compared to healthy subjects. No other significant differences were detected between the two groups for any of the variables (as listed in table 2).

\section{Macrophage Function in Response to GT Treatment}

Zymosan phagocytosis data from 1 'normal' subject with a very high sputum neutrophil count was unusable due to difficulties in gating an adequate number of macrophages for analysis by FCM. Data from this subject were excluded from analysis: thus, there were only 5 subjects in the normal group for this assay. A statistics summary of the $\mathrm{p}$ values for each outcome variable is provided in table 3.

\section{Uptake of Zymosan A Bioparticles}

Baseline values (i.e. no exposure to GT) for all the phagocytic parameters were higher (not statistically significant) for macrophages from allergic asthmatics compared to healthy controls (fig. 2). Multivariate analysis of the combined (healthy and asthmatic) groups showed that, although treatment with GT did not result in a significant change in the overall percentage of macrophages which had engulfed or attached to particles, there was a significant interaction $(\mathrm{p}=0.02)$ between GT treatment and allergic status, with the change approaching significance within the asthmatic group ( $\mathrm{p}=0.057)$. However, in the combined groups, multivariate analysis showed that GT treatment caused an overall significant decrease $(\mathrm{p}=0.04)$ in the ratio of cell-associated particles which were actually internalized, as opposed to particles remaining attached to the external cell surface. When considered individually, this effect was significant only in the asthmatic group ( $\mathrm{p}=0.02)$ and not in the healthy controls. Thereby, the two groups responded differently to GT treatment, and the effect was more pronounced in allergic asthmatics than healthy controls.

\section{Cell Surface Immunophenotype in Response to GT Treatment}

Changes in the expression of leukocyte cell surface proteins were measured by FCM as changes in the MFI of 


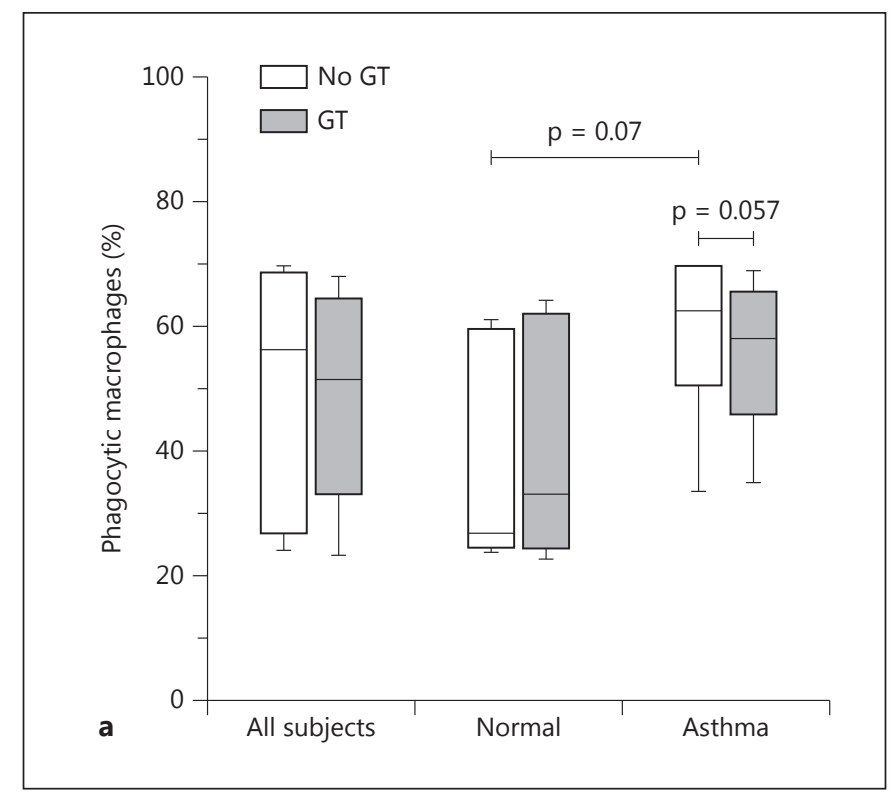

Fig. 2. Phagocytic uptake of zymosan A bioparticles by sputum macrophages, shown as percent phagocytic cells (a) and ratio of internalized/external particles (b). The baseline value (i.e. no exposure to GT) for particle internalization was higher, though not significant, for allergic asthmatics compared to healthy controls. GT treatment did not result in a significant change in the percentage of

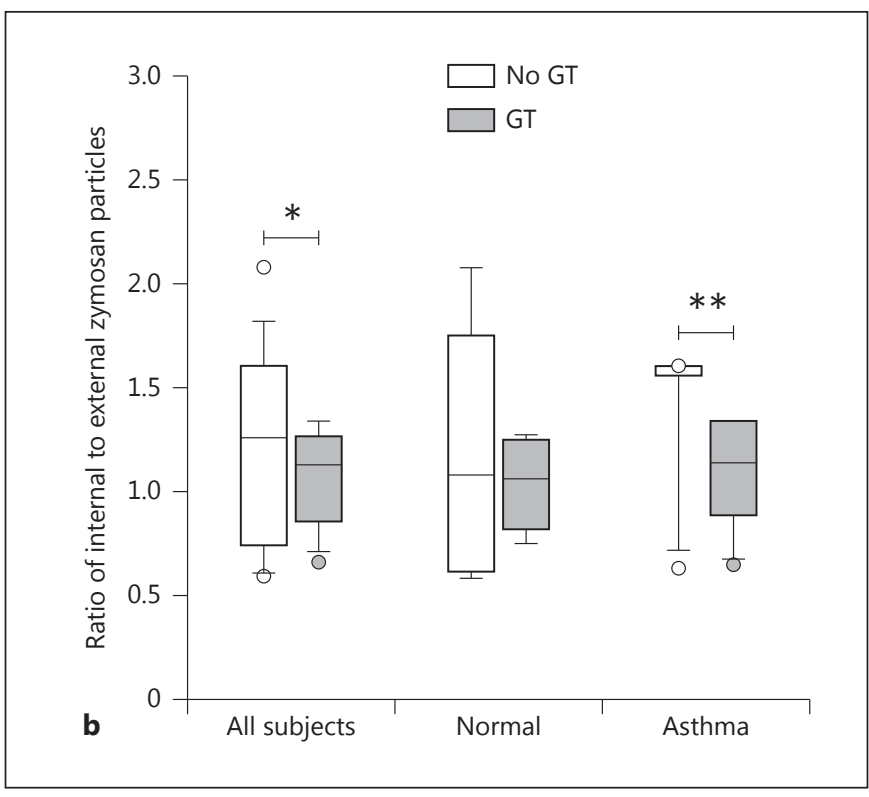

phagocytic cells. However, there was a significant interaction $(\mathrm{p}=$ 0.02 ) between GT treatment and allergic status, with the change approaching significance within the asthmatic group $(\mathrm{p}=0.057)$. GT treatment caused a significant $(* p=0.04)$ decrease in the ratio of internal/external particles in the combined healthy and allergic groups (all subjects), as well as in the allergic subgroup $(* * \mathrm{p}=0.02)$. the gated population. In general, treatment of cells with GT had a downregulating effect on the expression of selected cell surface proteins on sputum cells (fig. 3), including those with primary importance to both innate (CD206, CD16/Fc $\gamma$ RIII and CD36; fig. 4) and adaptive immune responses (HLA-DR, CD86 and CD40; fig. 5). We found no significant GT-induced changes in the expression of other surface proteins, including CD64/ Fc $\gamma$ RI, CD11b/CR3 or CD14/lipopolysaccharide receptor for macrophages. For some markers, we again found a significant effect of GT in allergic asthmatic subjects but could not detect a significant effect in the combined group, which might most likely be explained by the small number of subjects in each group. In addition, as can be seen in the graphs, mean baseline values for many of the surface markers were higher in allergic asthmatics than in healthy subjects. A statistical summary of the $\mathrm{p}$ values for each outcome variable is provided in table 3.

\section{Innate Immune Response Markers}

The macrophage mannose receptor (CD206) is a type C scavenger receptor (SR-C1, SRCL-1) similar to type A scavenger receptors but also having a C-type lectin/car- bohydrate recognition domain. It is important for phagocytosis of carbohydrates, glycoprotein and other molecules, and also functions in the presentation of mannosebearing antigens to $T$ cells by macrophages and a subset of dendritic cells. Multivariate analysis showed that GT treatment had a significant $(\mathrm{p}=0.02)$ downregulating effect on CD206 expression on sputum macrophages in the combined healthy and allergic groups (fig. 4a). When looking at the individual groups alone, we found a significant GT treatment effect in the allergic group ( $\mathrm{p}=$ 0.04 ) but not in the healthy group.

$\mathrm{Fc} \gamma$ receptors including $\mathrm{CD} 64 / \mathrm{Fc} \gamma \mathrm{RI}, \mathrm{CD} 32 / \mathrm{Fc} \gamma \mathrm{RII}$ and $\mathrm{CD} 16 / \mathrm{Fc} \gamma \mathrm{RIII}$ are important for phagocytosis of opsonized materials (e.g. bacteria and other microbes, antigen-antibody complexes and particles) by phagocytic cells. Relative to controls, the mean baseline CD64 expression was significantly lower on the macrophages of the asthmatic group $(19,332 \pm 1,237$ vs. $15,742 \pm 998, p=$ 0.05). Multivariate analysis of the combined groups showed no significant effect of GT treatment on CD64 expression by sputum macrophages. The mean baseline cell surface expression of CD16 on macrophages was slightly, but not significantly higher in asthmatic subjects. 


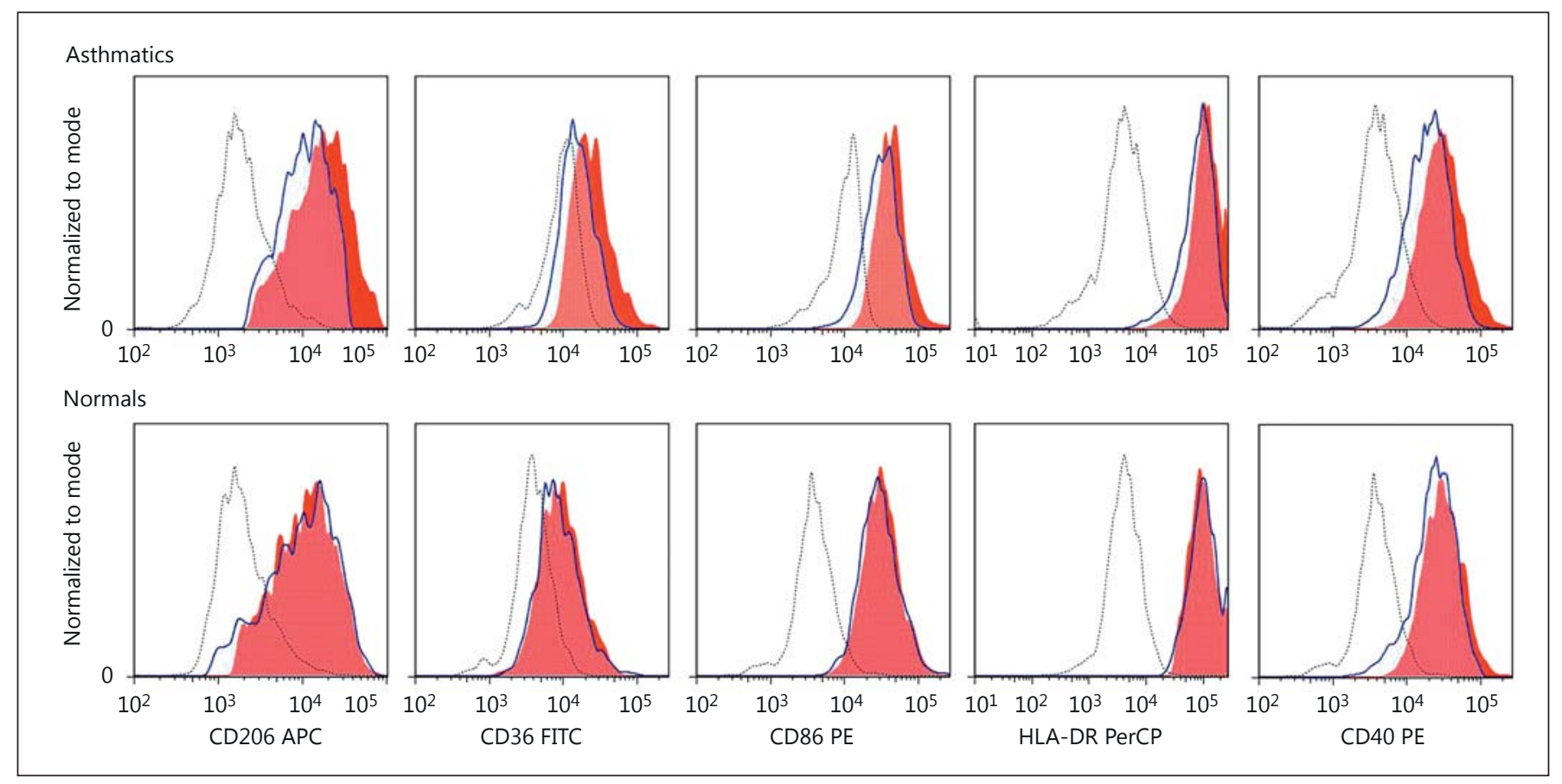

Fig. 3. Representative histograms depicting the differential expression of various surface proteins on sputum macrophages incubated with or without GT. Asthmatic subjects (top row) are compared with normal healthy subjects (bottom row). Dotted lines (no fill) represent isotype controls. Histograms for GT-treated macrophages (solid blue line, tinted fill) overlie the untreated macro-

Multivariate analysis of the combined groups showed a significant effect of GT treatment on the expression of CD16 on macrophages ( $p=0.03$; fig. $4 b)$.

We found no differences in the mean baseline expression of CD32, CD14 and CD11b/CR3 between groups, and multivariate analysis of the combined groups showed no significant effect of GT treatment on CD32, CD14 and CD11b/CR3 expression on macrophages.

CD36 is a type B scavenger receptor present on macrophages which functions as a receptor for endocytosis of lipoproteins, including oxidized LDL and high-density lipoproteins, fatty acids and a variety of other molecules. It has been shown to be downregulated by AT [34]. Baseline expression of CD36 was not different between groups. Multivariate analysis showed that expression of CD36 was significantly decreased on sputum macrophages following GT treatment $(9,975 \pm 1,425$ vs. $8,695 \pm 1,383, \mathrm{p}=0.03)$ in the combined groups, whereby both groups responded similarly (fig. 4c). Despite this, subgroup analyses showed a significant downregulating effect of GT in the allergic group $(\mathrm{p}=0.02)$ but not in the healthy subjects.

$\gamma$-Tocopherol and Macrophage Function in Asthma phages (solid red fill). Baseline (untreated) expression of surface proteins generally tended to be slightly higher on cells from asthmatics compared to healthy subjects. Similarly, expression tended to be decreased (i.e. histogram shifted to the left) on GT-treated macrophages from asthmatic subjects compared to healthy controls.

Adaptive Immune Response Markers

The mean baseline cell surface expression of CD86/ B7.2 was not significantly different between groups. Multivariate analysis of the combined groups showed that GT exposure caused significantly decreased expression of CD86/B7.2 on macrophages ( $\mathrm{p}=0.004$; fig. 5a). Subgroup analyses indicated that the response to GT was greater in the allergic subjects, with significantly decreased CD86 expression on macrophages $(p=0.03)$.

The mean baseline cell surface expression of HLA-DR was not significantly different between groups. In contrast to changes in CD86, there was no significant effect of GT treatment on the expression of HLA-DR by macrophages in either combined, healthy or allergic groups.

Expression of CD40/TNFR-5 (also a costimulatory molecule for B cells) was significantly decreased on macrophages $(\mathrm{p}=0.03)$ following GT exposure for the combined groups, but no significant decrease was noted when groups were considered individually (fig. 5b). We found no significant differences in the mean baseline CD40 expression. 


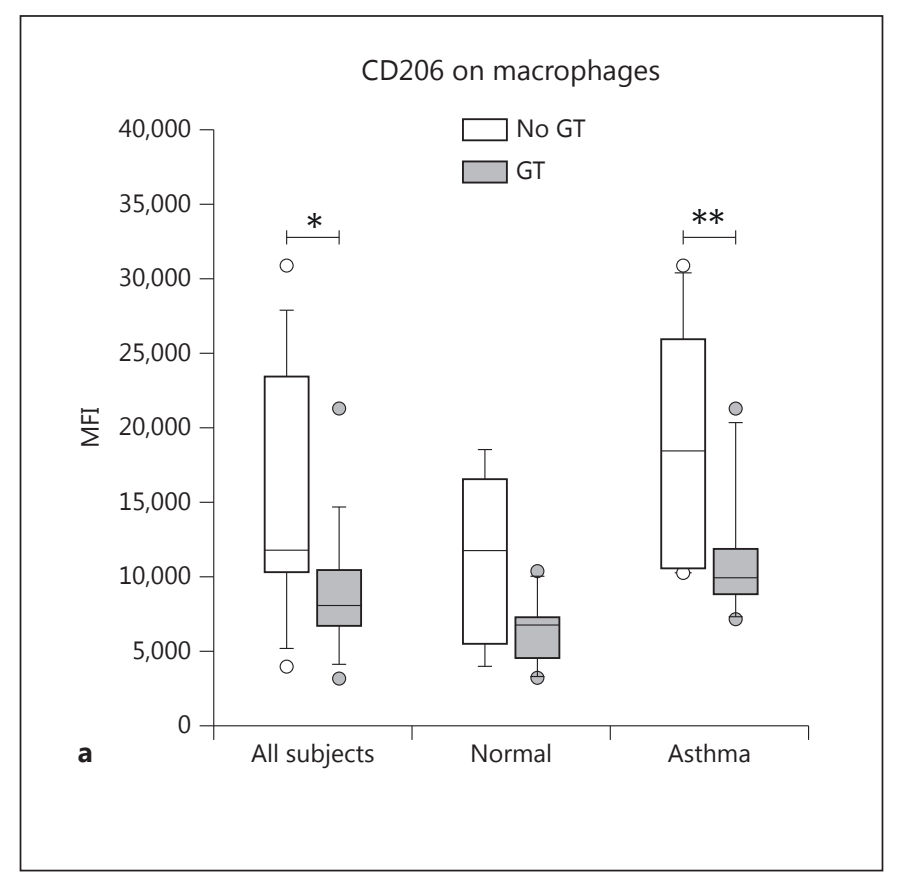

Fig. 4. Surface markers related to phagocytosis (innate immunity) with significant changes on sputum macrophages upon GT treatment. Expression of CD206 (a) was significantly downregulated in the combined healthy and allergic groups $(* \mathrm{p}=0.02)$ as well as in the allergic subgroup $\left({ }^{* *} \mathrm{p}=0.04\right)$. CD16 (b) was significantly downregulated in the combined groups $(* p=0.03)$. CD36 (c) was significantly decreased in the combined groups $\left({ }^{*} \mathrm{p}=0.03\right)$ as well as in the allergic subgroup $(* * \mathrm{p}=0.02)$.

\section{Discussion}

A major function of lung macrophages is the phagocytic uptake of inhaled and deposited particles for their clearance from the epithelial surfaces [35]. In order to study the effects of GT on airway macrophage function, we examined the effects of ex vivo GT treatment on spu-
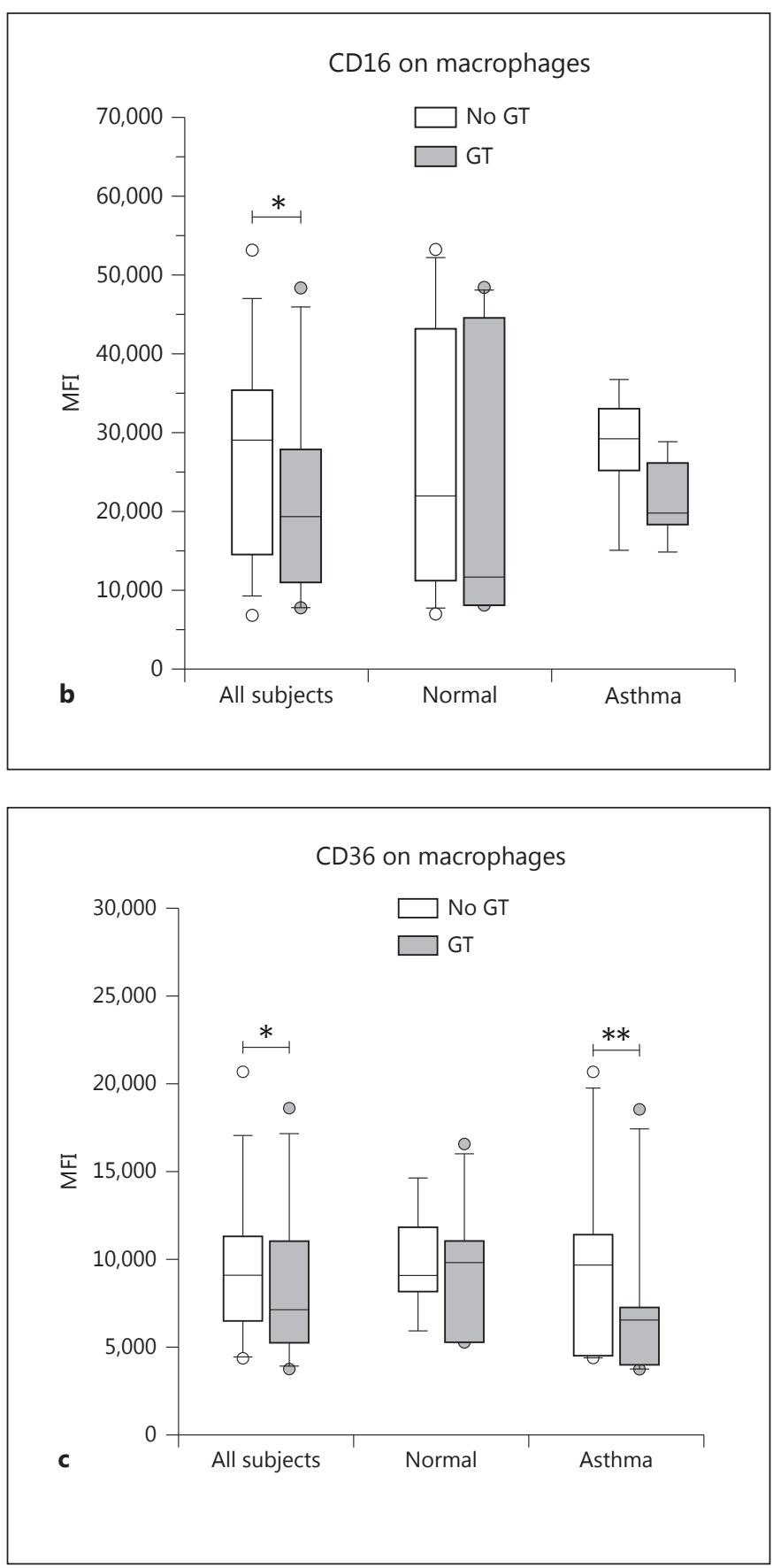

tum cell phagocytic activity and expression of cell surface proteins associated with both innate and adaptive immune function. Our results show that ex vivo GT treatment of sputum-derived airway macrophages caused decreases in certain phagocytic indices, downregulated expression of specific cell surface proteins and that atopic status appears to be an important factor. 

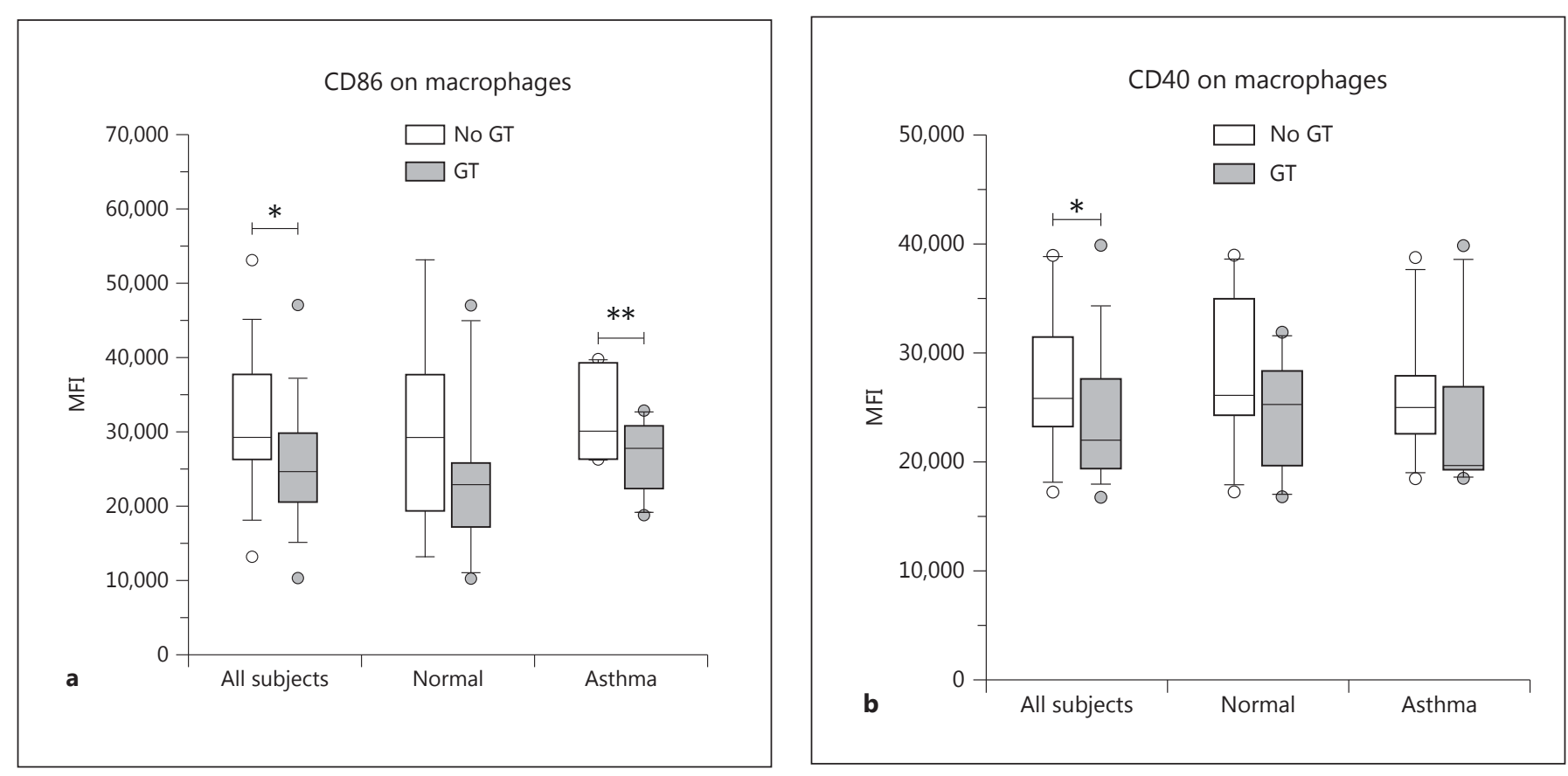

Fig. 5. Surface markers mainly related to adaptive immunity with significant changes on sputum macrophages upon GT treatment. Expression of CD86 (a) was significantly decreased in the combined healthy and allergic groups $\left({ }^{*} \mathrm{p}=0.004\right)$ as well as in the allergic subgroup $\left({ }^{* *} \mathrm{p}=0.03\right)$. CD40 (b) was significantly downregulated for the combined groups $(* \mathrm{p}=0.03)$.

These findings suggest that GT modulates macrophage activation and is consistent with findings in earlier studies $[28,34,36,37]$.

Our findings point to enhanced activity of airway surface macrophages in mild allergic asthma, as the baseline percentage of phagocytic cells is marginally higher (not statistically significant) in the asthmatics relative to the healthy subjects (fig. 2). This correlates with previous studies, where we have shown significantly increased in vivo uptake of inhaled particles and ex vivo phagocytosis by airway macrophages in subjects with mild allergic asthma compared to healthy controls [20]. Despite the higher baseline phagocytic activity in macrophages from allergic asthmatics, we were unable to detect a significant effect of GT treatment on the overall percentage of cells which phagocytized or attached to zymosan bioparticles in either healthy or allergic asthmatic cohorts. There was, however, a significant interaction between allergy status and GT treatment on the overall percentage of phagocytic macrophages, with a trend towards a significant effect of GT ( $p=0.057)$ in the asthmatic group. In addition, the proportion of attached zymosan bioparticles which were actually internalized (ratio of internal to external particles) was decreased following GT treatment (combined groups) suggesting that, though it did not affect attachment of particles, GT treatment impaired the ability of cells to internalize attached particles. These effects were consistently observed in the allergic asthmatic group, indicating a differential effect of GT in atopic versus nonatopic individuals. The exact molecular mechanisms for these differential effects are unclear and warrant further investigation.

The mechanism for the GT-induced inhibition of phagocytosis and particle internalization is unclear, but may be related to the modulation of surface receptors or perhaps by effects on cytoskeletal elements. While we did not examine the cytoskeleton, there is evidence that vitamin E (AT) inhibits monocyte adhesion and migration by interfering with actin polymerization [38]. Although uptake of IgG-opsonized zymosan A bioparticles is likely mediated primarily through Fc-receptor-mediated phagocytosis, complement receptors and scavenger receptors may also contribute to their uptake by macrophages. It is plausible and likely that receptors such as CD206 and other scavengers (CD163, CD204 and MARCO) or pathogen-associated molecular pattern receptors also partici- 
pate in the capture and endocytosis of zymosan particles. If so, differential downregulation of such receptors (e.g. CD206) could at least partially explain some of our findings on phagocytosis of zymosan bioparticles, especially in the asthmatic subjects where there was a significant effect of GT on CD206 expression. Our study suggests that antigens of a particulate nature may be less susceptible to endocytosis and subsequent antigen processing.

There is little available information on the effects of GT on the expression of cell surface molecules associated with antigen presentation. Consistent with our findings, Betjes et al. [36] reported decreased expression of MHC I and the costimulatory molecules CD86 and CD40 on blood monocytes associated with the use of vitamin E-coated dialysis membranes in hemodialysis patients. We did not study the effects of GT on T-cell function or of antigen processing and presentation by sputum antigen-presenting cells. However, we can speculate that the GT-induced downregulation of CD86 on macrophages in allergic asthmatics may impair antigen presentation.

Decreased CD36 (SR-B) expression is consistent with the literature on AT [37], including ex vivo studies using monocyte-derived human macrophages [34]. CD36 is also a receptor for oxidized LDL and is highly expressed on lipid-laden macrophages in atherosclerotic vascular lesions [39]. In the circulating blood, tocopherols are transported in lipoprotein carriers [40], and a major route of cellular uptake is via receptor-mediated endocytosis through type B scavenger receptors, SR-B1 and CD36. There is also evidence that GT may be preferentially metabolized to water-soluble forms to a greater extent than AT [41] and may gain entry into cells by an alternate mechanism. GT-induced downregulation of CD206 (SR-C1, macrophage mannose receptor) is consistent with the effects of AT on other scavenger receptors [e.g. CD36, as well as CD163 and CD204 (both MSRA1-type receptors)]. There is evidence that GT may be less efficient than AT at downregulating SR activity [42]; however, we have no data on the comparative effects of GT and AT on the expression of either CD36 (SR-B) or CD206 (SR-C1).

\section{Limitations of the Study}

We recognize it is unlikely that the high concentration of GT in our ex vivo study could be achieved in either plasma or airway surface secretions via oral dietary supplementation. The molar concentration used in our study $(300 \mu \mathrm{M})$ is 3 - to 30 -fold higher than concentrations of AT [34] or GT [13] used in previous in vitro studies and 40- to 200-fold higher than plasma GT concentrations in humans $[7,43]$. Reported AT concentrations in induced sputum are much lower, ranging from $100 \mathrm{nM}$ to $5.5 \mu \mathrm{M}$ $[43,44]$, and sputum GT concentration has been measured at approximately $100 \mathrm{~nm}$ [43]. Additional studies using lower concentrations of GT are warranted to determine if our findings remain valid at more physiologic concentrations.

We are aware that, due to the relatively small number of subjects, some of our comparisons are underpowered, which likely affected our ability to detect significant effects of GT treatment or allergy status for some parameters. Nevertheless, we were able to detect robust statistically significant changes in certain phagocytic indices and the expression of some surface proteins associated with innate and adaptive immune responses. Moreover, the data coherently show that GT has an effect generally consistent with downregulation of innate and adaptive immune function and that there is a differential effect in healthy versus allergic asthmatic individuals.

In conclusion, we showed in this novel study on sputum macrophages a downregulating effect of GT on surface proteins related to innate and adaptive immunity, whereby the asthmatic status was an important factor. In addition, GT had an attenuating effect on the more activated macrophages in asthmatic subjects, as it decreased certain phagocytic indices and surface proteins associated with antigen presentation by these cells. This study confirms that GT exerts differential effects on airway macrophage function in mild allergic asthmatics versus healthy individuals and supports findings of previous studies in animals which indicate GT supplementation may be beneficial in the treatment or prevention of allergic airway inflammation. These findings further our understanding of the role of airway surface macrophages in host defense, and provide a basis for further investigation into the effects of GT treatment on macrophage function, particularly in allergic asthmatic populations.

\section{Acknowledgments}

We thank Martha Almond, Carole Robinette, Sally Ivins, Margaret Herbst, Lynne Newlin-Clapp, Heather Wells and Fernando Dimeo for their technical assistance in this study.

This research was funded in part by grants from the National Center for Complementary and Alternative Medicine at the National Institutes of Health (P01AT002620) as well as cooperative agreement CR 83346301 from the US Environmental Protection Agency. Although the research described in this article has been funded wholly or in part by the United States Environmental Protection Agency through cooperative agreement CR 83346301 with 
the Center for Environmental Medicine and Lung Biology at the University of North Carolina at Chapel Hill, it has not been subjected to the Agency's required peer and policy review and therefore does not necessarily reflect the views of the Agency, and no official endorsement should be inferred. Mention of trade names or commercial products does not constitute endorsement or recommendation for use.

\section{Disclosure Statement}

None of the authors declared any conflict of interest related to this paper.

\section{References}

1 Cantorna MT, Zhu Y, Froicu M, Wittke A: Vitamin D status, 1,25-dihydroxyvitamin D3, and the immune system. Am J Clin Nutr 2004; 80(6 suppl):1717S-1720S.

-2 Dworski R, Han W, Blackwell TS, Hoskins A, Freeman ML: Vitamin E prevents NRF2 suppression by allergens in asthmatic alveolar macrophages in vivo. Free Radic Biol Med 2011;51:516-521.

>3 Lim Y, Vasu VT, Valacchi G, Leonard S, Aung HH, Schock GC, Kenyon NJ, Li C, Traber MG, Cross CE: Severe vitamin E deficiency modulates airway allergic inflammatory responses in the murine asthma model. Free Radic Res 2008;42:387-396.

4 Poon AH, Laprise C, Lemire M, Montpetit A, Sinnett D, Schurr E, Hudson TJ: Association of vitamin D receptor genetic variants with susceptibility to asthma and atopy. Am J Respir Crit Care Med 2004;170:967-973.

5 Singh U, Devaraj S, Jialal I: Vitamin E, oxidative stress, and inflammation. Annu Rev Nutr 2005;25:151-174

6 Wagner JG, Jiang Q, Harkema JR, Illek B, Patel DD, Ames BN, Peden DB: Ozone enhancement of lower airway allergic inflammation is prevented by gamma-tocopherol. Free Radic Biol Med 2007;43:1176-1188.

7 Wiser J, Alexis NE, Jiang Q, Wu W, Robinette C, Roubey R, Peden DB: In vivo gamma tocopherol supplementation decreases systemic oxidative stress and cytokine responses of human monocytes in normal and asthmatic subjects. Free Radic Biol Med 2008;45:40-49.

-8 Reiter E, Jiang Q, Christen S: Anti-inflammatory properties of alpha- and gamma-tocopherol. Mol Aspects Med 2007;28:668-691.

-9 Cook-Mills JM, McCary CA: Isoforms of vitamin $\mathrm{E}$ differentially regulate inflammation. Endocr Metab Immune Disord Drug Targets 2010;10:348-366.

10 McCary CA, Abdala-Valencia H, Berdnikovs S, Cook-Mills JM: Supplemental and highly elevated tocopherol doses differentially regulate allergic inflammation: reversibility of $\alpha$-tocopherol and $\gamma$-tocopherol's effects. J Immunol 2011;186:3674-3685.

11 Birnikovs S, Abdala-Valencia H, McCary C, Somand M, Cole R, Carcia A, Bryce P, CookMills JM: Isoforms of vitamin E have opposing immunoregulatory functions during inflammation by regulating leukocyte recruitment. J Immunol 2009;182:4395-4405.
12 Jiang Q, Ames BN: Gamma-tocopherol, but not alpha-tocopherol, decreases proinflammatory eicosanoids and inflammation damage in rats. FASEB J 2003;17:816-822.

13 Jiang Q, Elson-Schwab I, Courtemanche C, Ames BN: Gamma-tocopherol and its major metabolite, in contrast to alpha-tocopherol, inhibit cyclooxygenase activity in macrophages and epithelial cells. Proc Natl Acad Sci USA 2000;97:11494-11499.

14 Jiang Q, Lykkesfeldt J, Shigenaga MK, Shigeno ET, Christen S, Ames BN: Gamma-tocopherol supplementation inhibits protein nitration and ascorbate oxidation in rats with inflammation. Free Radic Biol Med 2002;33: 1534-1542.

15 Devaraj S, Traber MG: Gamma-tocopherol, the new vitamin E. Am J Clin Nutr 2003;77: 530-531.

16 Wagner JG, Harkema JR, Jiang Q, Illek B, Ames BN, Peden DB: Gamma-tocopherol attenuates ozone-induced exacerbation of allergic rhinosinusitis in rats. Toxicol Pathol 2009; 37:481-491.

17 Wagner JG, Jiang Q, Harkema JR, Ames BN, Illek B, Roubey RA, Peden DB: Gamma-tocopherol prevents airway eosinophilia and mucous cell hyperplasia in experimentally induced allergic rhinitis and asthma. Clin Exp Allergy 2008;38:501-511.

18 Alexis NE, Muhlebach MS, Peden DB, Noah TL: Attenuation of host defense function of lung phagocytes in young cystic fibrosis patients. J Cyst Fibros 2006;5:17-25.

19 Alexis NE, Soukup J, Nierkens S, Becker S: Association between airway hyperreactivity and bronchial macrophage dysfunction in individuals with mild asthma. Am J Physiol Lung Cell Mol Physiol 2001;280:L369-L375.

20 Lay JC, Alexis NE, Zeman KL, Peden DB, Bennett WD: In vivo uptake of inhaled particles by airway phagocytes is enhanced in patients with mild asthma compared with normal volunteers. Thorax 2009;64:312-320.

21 Baehner RL, Boxer LA, Ingraham LM, Butterick C, Haak RA: The influence of vitamin E on human polymorphonuclear cell metabolism and function. Ann NY Acad Sci 1982; 393:237-250.

22 Bergman M, Salman H, Djaldetti M, Fish L, Punsky I, Bessler $\mathrm{H}$ : In vitro immune response of human peripheral blood cells to vitamins $C$ and E. J Nutr Biochem 2004;15:45-50.
23 Harris RE, Boxer LA, Baehner RL: Consequences of vitamin-E deficiency on the phagocytic and oxidative functions of the rat polymorphonuclear leukocyte. Blood 1980; 55:338-343.

24 Mukherjee R: Selenium and vitamin E increases polymorphonuclear cell phagocytosis and antioxidant levels during acute mastitis in riverine buffaloes. Vet Res Commun 2008;32: 305-313.

25 Niu ZY, Liu FZ, Yan QL, Li WC: Effects of different levels of vitamin $\mathrm{E}$ on growth performance and immune responses of broilers under heat stress. Poult Sci 2009;88:2101-2107.

-26 Del Rio M, Ruedas G, Medina S, Victor VM, De la Fuente M: Improvement by several antioxidants of macrophage function in vitro. Life Sci 1998;63:871-881.

27 Moraguchi S, Kobayashi N, Kishino Y: High dietary intakes of vitamin $\mathrm{E}$ and cellular immune functions in rats. J Nutr 1990;120: 1096-2011.

28 De la Fuente M, Carazo M, Correa R, Del Rio M: Changes in macrophage and lymphocyte functions in guinea-pigs after different amounts of vitamin $\mathrm{E}$ ingestion. Br J Nutr 2000;84:25-29.

29 Alexis NE, Eldridge MW, Peden DB: Effect of inhaled endotoxin on airway and circulating inflammatory cell phagocytosis and CD11b expression in atopic asthmatic subjects. J Allergy Clin Immunol 2003;112:353-361.

30 Alexis NE, Lay JC, Zeman K, Bennett WD, Peden DB, Soukup JM, Devlin RB, Becker S: Biological material on inhaled coarse fraction particulate matter activates airway phagocytes in vivo in healthy volunteers. J Allergy Clin Immunol 2006;117:1396-1403.

-31 Alexis NE, Lay JC, Zeman KL, Geiser M, Kapp $\mathrm{N}$, Bennett WD: In vivo particle uptake by airway macrophages in healthy volunteers. Am J Respir Cell Mol Biol 2006;34:305-313.

32 Alexis NE, Soukup JM, Ghio A, Becker S: Sputum phagocytes from healthy individuals are functional and activated: a flow cytometric comparison with cells in bronchoalveolar lavage and peripheral blood. Clin Immunol 2000;97:21-32.

33 Lay JC, Peden DB, Alexis NE: Flow cytometry of sputum: assessing inflammation and immune response elements in the bronchial airways. Inhal Toxicol 2011;23:392-406. 
34 Devaraj S, Hugou I, Jialal I: Alpha-tocopherol decreases CD36 expression in human monocyte-derived macrophages. J Lipid Res 2001; 42:521-527.

35 Geiser M: Update on macrophage clearance of inhaled micro- and nanoparticles. J Aerosol Med Pulm Drug Deliv 2010;23:207-217.

36 Betjes MGH, Hoekstra FME, Klepper M Postma SM, Vaessen LMB: Vitamin E-coated dialyzer membranes downregulate expression of monocyte adhesion and co-stimulatory molecules. Blood Purif 2004;22:510-517.

37 Ricciarelli R, Zingg JM, Azzi A: Vitamin E reduces the uptake of oxidized LDL by inhibiting CD36 scavenger receptor expression in cultured aortic smooth muscle cells. Circulation $2000 ; 102: 82-87$.
38 Mine S, Tabata T, Wada Y, Fujisaki T, Iida T, Noguchi N, Niki E, Kodama T, Tanaka Y: Oxidized low density lipoprotein-induced LFA1-dependent adhesion and transendothelial migration of monocytes via the protein kinase C pathway. Atherosclerosis 2002;160:281288.

39 Liu M, Wallmon A, Olsson-Mortlock C, Wallin R, Saldeen T: Mixed tocopherols inhibit platelet aggregation in humans: potential mechanisms. Am J Clin Nutr 2003;77:700706.

40 Hacquebard M, Carpentier YA: Vitamin E: absorption, plasma transport and cell uptake. Curr Opin Clin Nutr Metab Care 2005;8:133138.
1 Gao R, Stone WL, Huang T, Papas A, Qui M The uptake of tocopherols by RAW 264.7 macrophages. Nutr J 2002;1:2.

42 Teupser D, Thiery J, Seidel D: Alpha-tocopherol down-regulates scavenger receptor activity in macrophages. Atherosclerosis 1999;144: 109-115.

43 Hernandez ML, Zhou H, Zhou B, Robinette C, Crissman K, Hatch G, Alexis NE, Peden D: Combination treatment with high-dose vitamin $\mathrm{C}$ and alpha-tocopherol does not enhance respiratory-tract lining fluid vitamin $\mathrm{C}$ levels in asthmatics. Inhal Toxicol 2009;21: 173-181.

44 Wood LG, Garg ML, Blake RJ, Simpson JL, Gibson PG: Oxidized vitamin E and glutathione as markers of clinical status in asthma. Clin Nutr 2008;27:579-586. 